\title{
Improvement in Water Resistance of Desulfurized Gypsum by Novel Modification of Silicone Oil Paraffin Composite Emulsion-based Waterproofing Agent
}

\author{
Jing-Yu Cao****, Jin-Peng Li**, Ya-Mei Jiang**, Su-Lei Wang**, \\ Yi Ding (1D)***,t, and Won-Chun Oh (D) **** \\ *Anhui Key Laboratory of Advanced Building Materials, Anhui Jianzhu University, Hefei Anhui 230022, P. R. China \\ ** School of Materials and Chemical Engineering, Anhui Jianzhu University, Hefei Anhui 230601, P. R. China \\ ***Department of Advanced Materials Science \& Engineering, Hanseo University, Seosan 31962, Korea
}

(Received September 17, 2019; Accepted October 18, 2019)

\begin{abstract}
In this study, dimethyl silicone oil and liquid paraffin were combined and subsequently emulsified; the resulting mixture was innovatively incorporated into desulfurized gypsum to resolve its drawback of a poor water resistance. The waterproof mechanism of the composite emulsion and liquid paraffin emulsion with mass fractions of $1 \%, 2 \%, 3 \%$, and $4 \%$ were investigated. The effect of the desulfurized gypsum on the waterproof performance and basic mechanical properties were also investigated. The configuration of the composite waterproofing agent was characterized by FTIR and ${ }^{1}$ HNMR. The results showed that, compared with the traditional liquid paraffin emulsion-based waterproofing agent, the softening coefficient of the silicone oil paraffin composite emulsion-based water-repellent agent was increased by $60 \%$ and attained a value of 0.89 . Combined with the waterproof mechanism and microscope morphology analysis of gypsum hydration products, the improvement in the water resistance of water resistance was primarily attributed to the formation of a silicone hydrophobic membrane between the crystals of the gypsum block; this ensured that water could not penetrate the crystal.
\end{abstract}

Key words : Desulfurization gypsum, Silicone oil paraffin composite emulsion, Softening coefficient, Waterproof mechanism

\section{Introduction}

$\mathrm{G}$ ypsum block is essentially used as a wall insulation material in buildings. It is primarily used for constructing the internal partition wall; further, it is light-weight, fireproof, and has noteworthy thermal insulation as well as seismic performance. However, due to the poor water resistance of construction products based on gypsum, it cannot meet the requirements for the development and use of architectural construction. ${ }^{1)}$ In recent years, international scholars $^{2-4)}$ have conducted in-depth research on the modification of gypsum for its characteristics owing to its wide application in green building materials. Meanwhile, numerous scholars ${ }^{5-7)}$ have studied the modification of desulfurization of gypsum in order to improve the resource utilization

\footnotetext{
Corresponding author : Yi Ding

E-mail : dyrqf@ahjzu.edu.cn

Tel : +86-13866159186 Fax : +86-0551-63828106

ORCID

https://orcid.org/0000-0002-3933-664X

${ }^{\ddagger}$ Corresponding author : Won-Chun Oh

E-mail : wc_oh@hanseo.ac.kr

Tel : +82-41-660-1337 Fax : +82-41-688-3352

ORCID

https://orcid.org/0000-0002-0154-7388
}

value of the industrial by-product obtained during the desulfurization of gypsum.

At present, several research teams have investigated many research areas pertaining to the improvement of the water-resistance of gypsum. Zhao Feng-qing ${ }^{8)}$ has studied the mixing of water repellent agents that are prepared by granular blast furnace slag, high calcium fly ash and some additives with calcined desulfurized gypsum; this was aimed at preparing a waterproof gypsum block. Khalil A.A. ${ }^{9)}$ has investigated the preparation of gypsum-based composites by mixing it with $0.2 \%-10 \%$ of unburned rice hulls, blast furnace slag, calcium carbonate and polyvinyl alcohol (PVA) to improve water resistance. Zhu $\mathrm{Cong}^{10)}$ has researched the effects of polyvinyl alcohol and polypropylene fibers on the workability, hydrodynamics, mechanical properties and water resistance of gypsum-based composites. Pervyshin G.N. ${ }^{11)}$ studied the structure and properties of an artificial modifier-modified gypsum composition based on metallurgical dust and multi-walled carbon nanotubes with improved water resistance and a softening coefficient of 0.85 . Domanskaya ${ }^{12)}$ studied the gypsum-based cementitious materials, emphasizing its environmental advantages over Portland cement and expounding the main methods to improve its water resistance. Khalil A.A. ${ }^{13)}$ researched about composite materials such as gypsum, silica sand, silica 
fume, silica gel, rice husk, slag, calcium carbonate, and PVA to show the improved mechanical properties and water resistance of gypsum. Our team has also done in-depth work in this field. Firstly, the Anhui industrial by-product gypsum was divided into detail, and its comprehensive utilization status was analyzed. ${ }^{14)}$ Secondly, some progress has been made in the research of desulfurized gypsum as a waterproofing agent, and a new type of building gypsumbased waterproofing agent has been prepared. ${ }^{15)}$ In addition, a new type of high-efficiency inorganic composite waterproofing agent has been prepared. ${ }^{16)}$

This work is based on the silicone polymer compound, namely: dimethyl silicone oil. It is observed that the liquid paraffin replaces a part of the silicone oil under the action of the compound emulsifier. After complete emulsification, the composite emulsion-based waterproofing agent for building gypsum is prepared. Compared with the traditional liquid paraffin emulsion-based waterproofing agent, the waterproofing agent synthesized in this study has less influence on the mechanical properties of the gypsum; further, it can significantly improve the softening coefficient of the gypsum.

\section{Experimental Procedure}

\subsection{Experimental materials}

Liquid paraffin (AR, 99\%, Shanghai Maclean Biochemical Technology Co., Ltd.); Dimethicone (industrial grade, commercially available product); Tween-80, (CP, Shanghai Maclean Biotechnology Co., Ltd.); Span-80 (Litter sorbitol oleate) (CP, Shanghai Maclean Biochemical Technology Co., Ltd.); Stearic acid $\left(98 \%\right.$, melting point $69^{\circ} \mathrm{C}-72^{\circ} \mathrm{C}$, Shanghai Maclean Biochemical Technology Co., Ltd.); Triethanolamine (AR, 98\%, Shanghai Maclean Biochemical Technology Co., Ltd.); OP-10 emulsifier (hydrophilic, hydroxyl value $87 \pm 10$, Shanghai Maclean Biochemical Technology Co., Ltd.); Desulfurization gypsum (Huainan Thermal Power Plant). The content of $\beta$-hemihydrate gypsum and dihydrate gypsum are $71.4 \%$ and $14.7 \%$, respectively. Meanwhile, the chemical composition and phase XRD spectrum of the desulfurized gypsum are shown in Table 1 and Fig. 1, respectively; the TG-DSC analysis curve is shown in Fig. 2; the particle size distribution curve is shown in Fig. 3.

\subsection{Preparation of paraffin emulsion}

We chose 80 parts of liquid paraffin, added 5 parts of tween-80 and span-80 sequentially, then stirred. We further added 240 parts of deionized water, warmed up to $85^{\circ} \mathrm{C}$, stirred for $80 \mathrm{~min}$ for full emulsification to obtain milky white slightly transparent emulsion, which is paraffin emulsion water repellent.

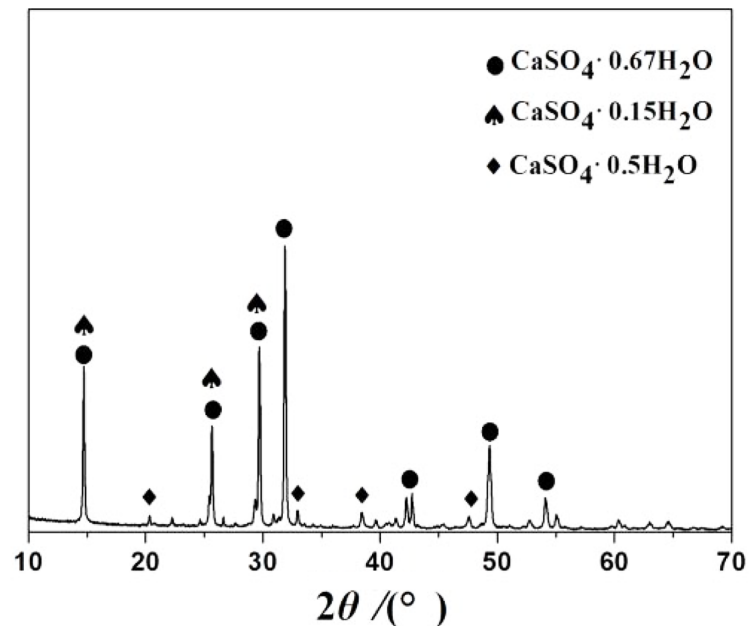

Fig. 1. The phase composition XRD pattern of desulphurization gypsum.

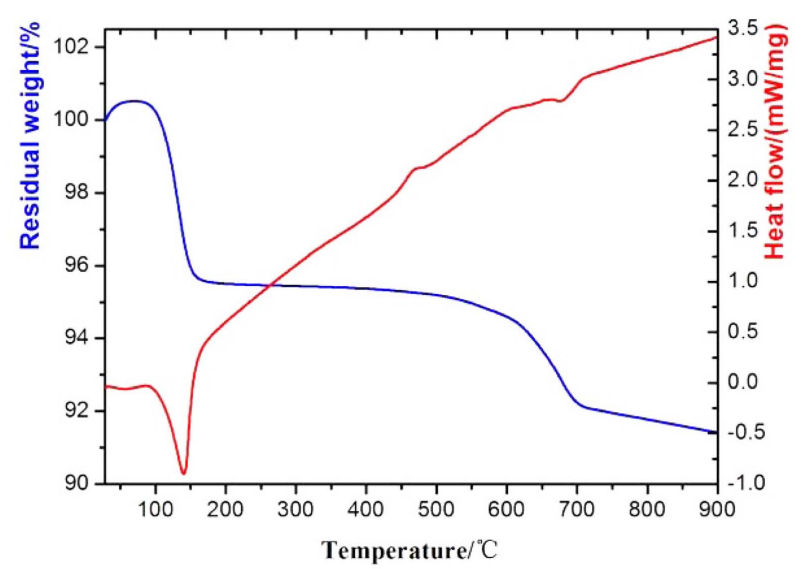

Fig. 2. TG analysis curve of desulphurization gypsum.

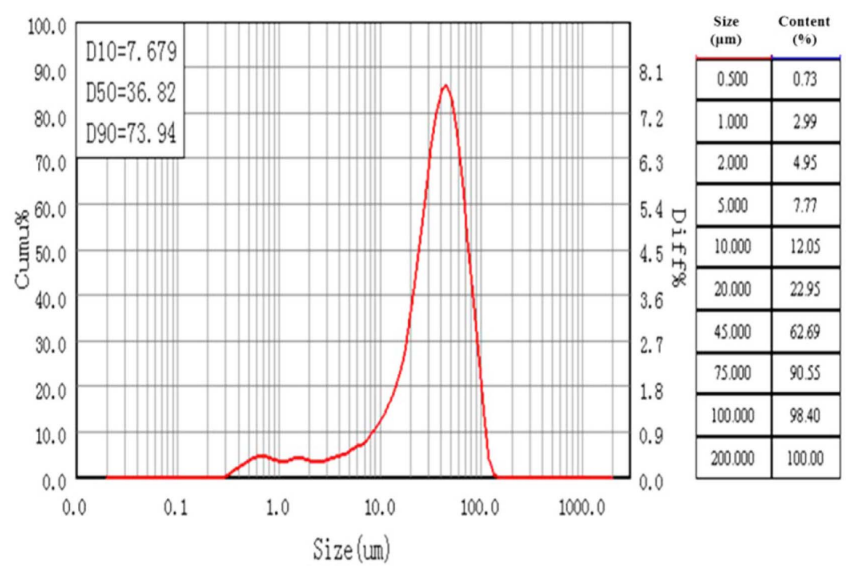

Fig. 3. Grain size distribution curve of desulphurization gypsum.

Table 1. Chemical Component of Desulphurization Gypsum

\begin{tabular}{ccccccccc}
\hline Chemical component & LOI & $\mathrm{SiO}_{2}$ & $\mathrm{Fe}_{2} \mathrm{O}_{3}$ & $\mathrm{Al}_{2} \mathrm{O}_{3}$ & $\mathrm{CaO}$ & $\mathrm{MgO}$ & $\mathrm{SO}_{3}$ & Crystal water \\
\hline Content (\%) & 11.76 & 2.86 & 0.48 & 0.91 & 37.45 & 0.77 & 43.11 & 5.64 \\
\hline
\end{tabular}




\subsection{Preparation of Dimethicone-Paraffin Compos- ite Emulsion}

Liquid paraffin replaces part of dimethyl silicone oil to prepare a composite emulsion with a mass fraction of $25 \%$. Using a laboratory-made compound emulsifier, Span80: Tween80: stearic acid: OP-10: triethanolamine has a mass ratio of 6:3:2:2:3. We took 200 parts of dimethyl silicone oil, 66 parts of liquid paraffin; the total mass of emulsifier is 16 parts. The stirring speed was $1500 \mathrm{r} / \mathrm{min}$. We further prepared 160 parts of preheated deionized water twice in oil bath condition at $80^{\circ} \mathrm{C}$, increased the stirring speed to 2000 $\mathrm{r} / \mathrm{min}$, and then, after half an hour, we added 40 parts of deionized water to dilute. We subsequently stirred at the speed of $1000 \mathrm{r} / \mathrm{min}$, stirred for $30 \mathrm{~min}$ until fully emulsified to obtain a white fine emulsion as a laboratory-made composite emulsion-based waterproofing agent. ${ }^{17}$

\subsection{Preparation and performance test of gypsum block}

2.4.1. Test of strength and softening coefficient

According to the National Standard "GB/T 17669.3-1999: Determination of the mechanical properties of building gypsum," determine the water consumption of the test standard consistency, $40 \mathrm{~mm} \times 40 \mathrm{~mm} \times 160 \mathrm{~mm}$ triple mold gypsum test block, need to be intensified after its hydration age. The test specimens were stored in the curing box immediately after demolding. During the entire hydration period, the temperature of the air in the curing box was $25^{\circ} \mathrm{C} \pm 2^{\circ} \mathrm{C}$, and the relative humidity was $90 \% \pm 5 \%$. After curing to the age, dry in a $40^{\circ} \mathrm{C} \pm 4^{\circ} \mathrm{C}$ oven to constant weight, and continue to heat in the oven at $80^{\circ} \mathrm{C}$ for $1 \mathrm{~h}$, take the dried test block for $24 \mathrm{~h}$ after the test is a saturated water test block. According to "GB /T 9776-2008 Building Gypsum," determine the strength of the dry and immersed gypsum block. The softening coefficient is the ratio of the breaking strength of the test block to the dry strength.

\subsubsection{Test of the water absorption rate}

We weighed the test piece $\left(\mathrm{M}_{1}\right)$ dried to a constant weight in an oven at $40^{\circ} \mathrm{C} \pm 4^{\circ} \mathrm{C}$, then immersed it in water at $20^{\circ} \mathrm{C} \pm 2$ ${ }^{\circ} \mathrm{C}$ for $24 \mathrm{~h}$. We took out the mass $\left(\mathrm{M}_{2}\right)$, and absorbed water: $\left.\left(\mathrm{M}_{2}\right)-\mathrm{M}_{1}\right) / \mathrm{M}_{1} \times 100 \%$.

\section{Results and Discussion}

\subsection{Effect of waterproofing agent on gypsum strength}

According to the blending amount of $0 \%, 1 \%, 2 \%, 3 \%$, and $4 \%$, the different amounts of emulsion-based waterproofing agents were added to the gypsum slurry, sequentially. The test piece was formed by triple trial molding cured for 7 days and dried to dryness. Fig. 4 shows the strength change of the saturated water gypsum test block after $24 \mathrm{~h}$ of water immersion, whereas Fig. 5 illustrates the strength change of the dry gypsum test block. The saturated water flexural strength of the entire water-repellent test blocks had increased to different degrees compared with the saturated

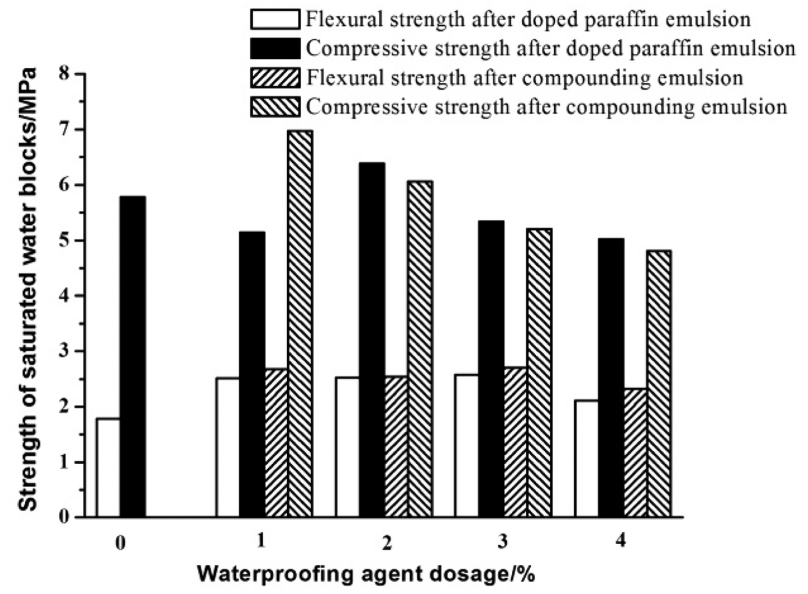

Fig. 4. Influence on the strength of saturated water blocks with the dosage of emulsion-based waterproofing agent.

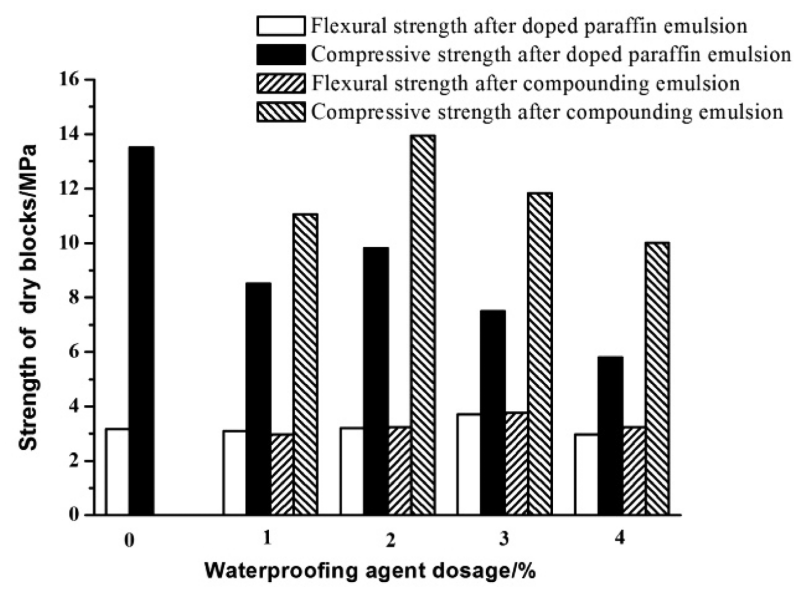

Fig. 5. Influence on the strength of dry blocks with the dosage of emulsion waterproofing agent.

water flexural strength of the blank test block. The flexural strength of the saturated water test block after blending with the paraffin emulsion was the same as the blending strength. With the addition of paraffin emulsion, the flexural strength of the saturated water test block increased first and then decreased proportionally to the mixing amount. The maximum flexural strength increased by $44 \%$ when the amount of paraffin emulsion was $3 \%$; the compressive strength also increased first, decreased, and gradually stabilized. The compressive strength of saturated water test block was increased by a maximum of $10.4 \%$ when the paraffin emulsion was $2 \%$. The flexural strength of the saturated water test block after the silicone oil paraffin composite emulsion-based waterproofing agent was first increased and then decreased slowly; It then reached the maximum when the blending amount was 3\% (the flexural strength increased by $51 \%$ ); the compressive strength increased first. The tendency to gradually decrease was much better than that of the paraffin-embedded gypsum plaster block and the blank gypsum sample and reached the highest at the 1\% content (the compressive strength increased by $21 \%$ ). After 
the paraffin emulsion was blended, the flexural strength increased first, decreased, and then stabilized. The strength was significantly lower than that of the blank gypsum, indicating that the incorporation of the paraffin emulsion had a negative effect on the gypsum strength. The flexural strength of the dry test piece, after incorporating the silicone oil paraffin composite emulsion-based waterproofing agent, changed by a small amount with an increase in the dosage. It subsequently became stable and slightly higher than the flexural strength of the blank gypsum test piece. Although the compressive strength was incorporated when the amount was $1 \%$, the strength of the gypsum, similar to paraffin, was much lower than that of the blank gypsum test block. This indicated that the silicone oil paraffin composite emulsion-based waterproofing agent did not have obvious adverse effects on the strength of the gypsum; further, the strength was improved. Compared with the traditional paraffin emulsion-based waterproofing agent, it can be applied to gypsum better.

\subsection{Effect of water repellent on gypsum softening coefficient and water absorption}

Figure 6 shows that the effect of the silicone oil paraffin composite emulsion-based waterproofing agent on the gypsum softening coefficient was significantly higher than that of the paraffin emulsion, and the softening coefficient has reached up to 0.89 . The softening coefficient has increased by $60 \%$ when the content was $1 \%$, and the paraffin emulsion increased by only $44 \%$. The softening coefficient ranges from 0 to 1 and the larger the value, the better the water-resistance of the desulfurized gypsum. With the increase in the amount of water repellent, the softening coefficient of gypsum added with silicone oil paraffin emulsion increased first and then decreased. It was significantly higher than that of paraffin emulsion. This indicated that the desulfurized gypsum of silicone oil paraffin emulsion- based waterproofing agents possessed superior water resistance.

Figure 7 shows the effect of two different water repellents

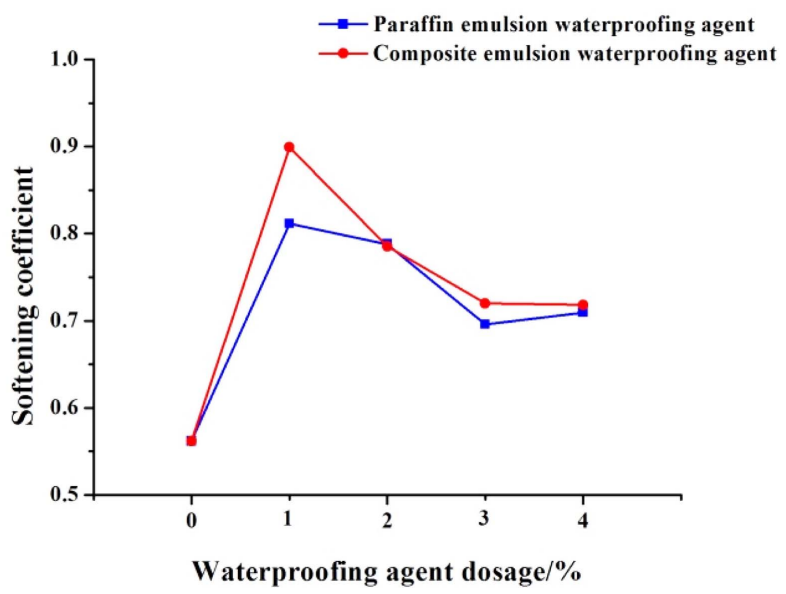

Fig. 6. Influence on softening coefficient of blocks with the dosage of emulsion-based waterproofing agent.

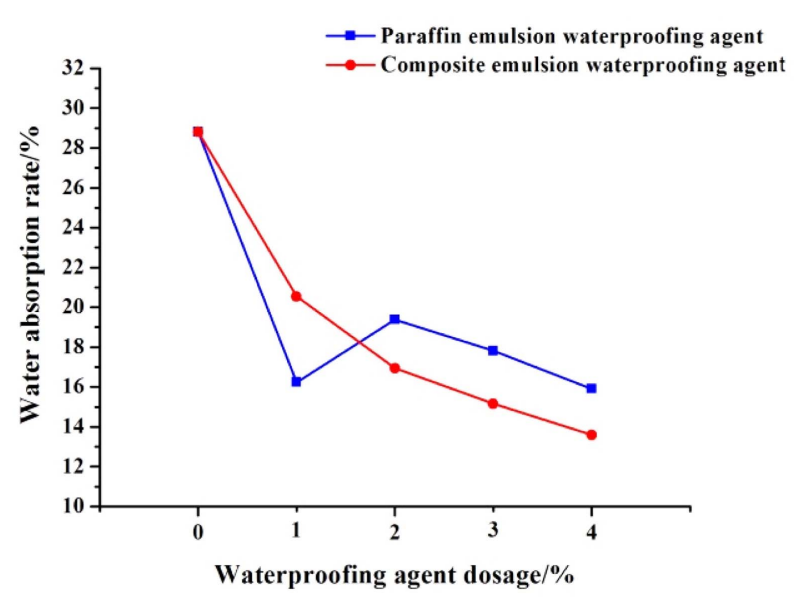

Fig. 7. Influence on water absorption of blocks with the dosage of emulsion-based waterproofing agent.

on the water absorption of the test block at different blending amounts. The water absorption of the test block was significantly reduced with the increase in the two different water repellents. The water absorption rate of the paraffin emulsion-based-waterproofing agent was lower than that of the composite emulsion at $1 \%$; this is because the paraffin wax was emulsified to form extremely fine spherical particles, which were suspended in water to form an oil-in-water continuous phase emulsion, so that the water absorption rate of the gypsum test block can be significantly reduced. However, with the increase in the amount of paraffin emulsion, a decrease in the mechanical strength was observed; this caused the water absorption rate to increase compared with $1 \%$. After the blending amount was more than $1 \%$, the water absorption of the test piece incorporating the paraffin silicone oil composite emulsion waterproofing agent was lowered faster. This indicated that the paraffin silicone oil composite emulsion-based waterproofing agent has significantly improved the softening coefficient of gypsum than the traditional paraffin emulsion-based waterproofing agent did;

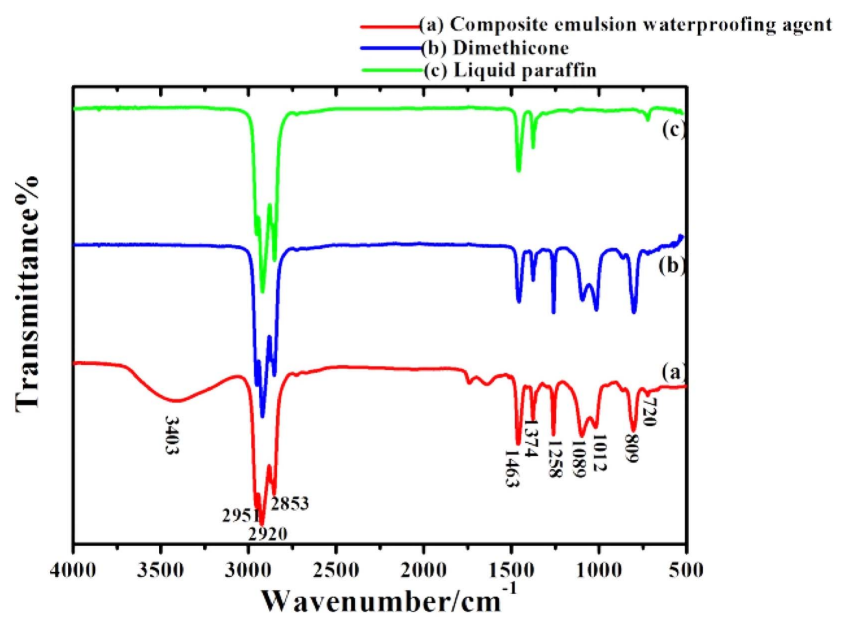

Fig. 8. IR spectrum curve of dimethicone and liquid paraffin in the composite emulsion-based waterproofing agent. 


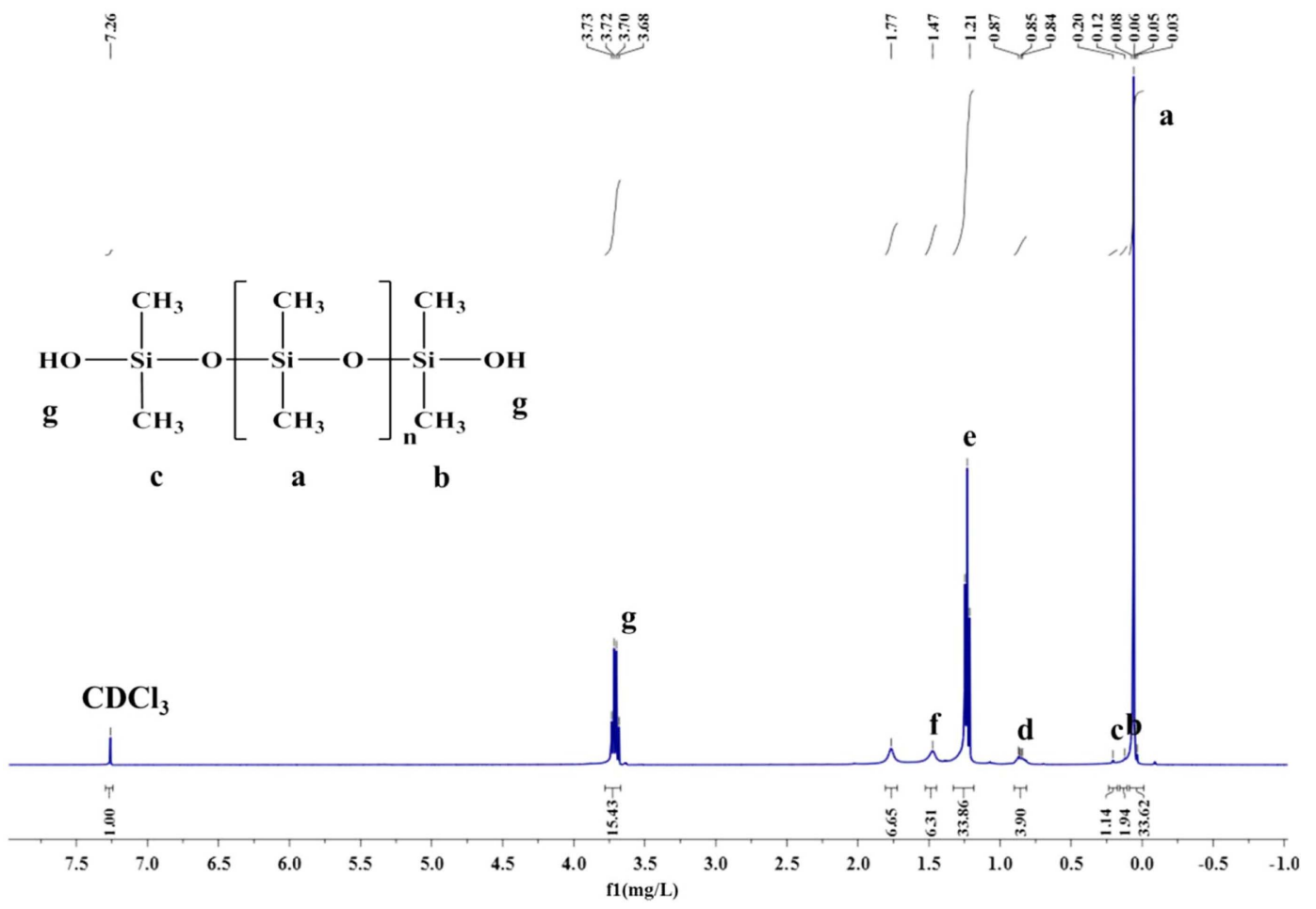

Fig. 9. ${ }^{1} \mathrm{H}$ NMR spectra of composite emulsion-based waterproofing agent.

further, the water absorption rate was also significantly reduced.

\subsection{Composition analysis of silicone oil paraffin composite emulsion waterproofing agent}

FTIR infrared detection was performed by American Thermo Fisher Scientific Nicolet 6700 Fourier transform infrared spectrometer after dimethyl silicone oil, liquid paraffin, silicone oil paraffin composite emulsion-based waterproofing agent were vacuum dried and dehydrated. Fig. 8 shows the infrared spectrum obtained.

The three groups of infrared spectra in Fig. 8 were compared, and the analysis results were shown in the figure. The peak of the hydroxyl group was around $3400 \mathrm{~cm}^{-1}$. The leftmost side of the figure showed a broad peak. According to the chemical formula of dimethyl silicone oil and liquid paraffin, there was no hydroxyl functional group, but it was at $3403 \mathrm{~cm}^{-1}$. There was a broad and relatively blunt peak. Because the water repellent was not sufficiently dried, this peak denotes a hydroxyl function of water molecules. The three peaks: $2951 \mathrm{~cm}^{-1}, 2920 \mathrm{~cm}^{-1}$, and $2853 \mathrm{~cm}^{-1}$ could be attributed to the hydrogen-bonding vibration of methyl $\left(\mathrm{CH}_{3}-\right)$ of dimethicone and liquid paraffin. The absorption peaks at $1463 \mathrm{~cm}^{-1}$ and $1374 \mathrm{~cm}^{-1}$ were caused by the asymmetric deformation vibration and symmetrical deformation vibration of the paraffin methyl group $\left(\mathrm{CH}_{3}-\right)$, respectively. The absorption peak at $1258 \mathrm{~cm}^{-1}$ was mainly caused by the deformation vibration of dimethyl silicone oil- $\mathrm{CH}_{3}$. The infrared absorption peaks at $1089 \mathrm{~cm}^{-1}$ and $1012 \mathrm{~cm}^{-1}$ were mainly caused by the stretching vibration of Si-O bond of dimethyl silicone oil; the absorption peak at $809 \mathrm{~cm}^{-1}$ was mainly composed of Si-C bond of dimethyl silicone oil. ${ }^{18)}$ $\mathrm{T}$ he absorption peak at $720 \mathrm{~cm}^{-1}$ was mainly caused by the in-plane rocking vibration of $-\mathrm{CH}_{2}$-methylene of liquid paraffin. ${ }^{19)}$ As aforementioned, the position of each functional group (bond) of the synthesized product was analyzed, and it was preliminarily determined that the composite emulsion-based waterproofing agent prepared in the laboratory was obtained by compounding silicone oil-paraffin.

The silicone oil paraffin composite emulsion-based waterproofing agent was purified and dried. It was then subjected to ${ }^{1} \mathrm{H}$-NMR detection by the German Brux Ascend Aeon 400 NMR spectrometer. The deuterated reagent $\mathrm{CDCl}_{3}$ was used as a solvent to detect the nuclear magnetic properties of the product, and some basic products were characterized. The nature of its nuclear magnetic resonance spectrum was as follows:

First, the peak position in the Fig. 9 was at $7.26 \mathrm{mg} / \mathrm{L}$, which was obviously the solvent peak of the deuterated reagent $\mathrm{CDCl}_{3}$. Due to incomplete drying, the product contained moisture and the peak position of the water was at $1.47 \mathrm{mg} / \mathrm{L}(\mathrm{f})$. The peak at the position of $3.68 \sim 3.73 \mathrm{mg} / \mathrm{L}$ (g) belonged to the silanol group in the polydimethylsiloxane, and the peak at $0.08 \mathrm{mg} / \mathrm{L}$ (a) denoted the silyl group. The peak positioned at $0.12 \mathrm{mg} / \mathrm{L}$ (b) represented $\mathrm{H}$ on the silicon methyl group attached to the silanol at the end of the molecular chain, and the peak at $0.20 \mathrm{mg} / \mathrm{L} \mathrm{(c)} \mathrm{was} \mathrm{the}$ molecular chain head end and the peak position of $\mathrm{H}$ on the silanol-bonded silicon methyl group. The main component of paraffin wax was normal paraffin, and so the peaks at 0.87 


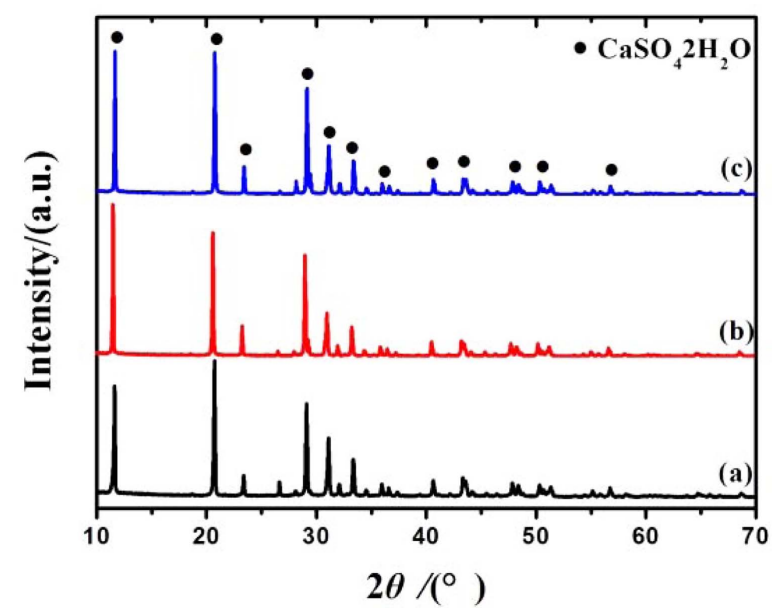

Fig. 10. XRD analysis of gypsum (the curve (a) was the XRD analysis of blank gypsum sample, curve (b) was the XRD analysis of gypsum sample to which $1 \%$ of a paraffin emulsion water repellent is added, curve (c) was the XRD analysis of gypsum sample to which a $1 \%$ silicone oil paraffin composite emulsion water repellent is added).
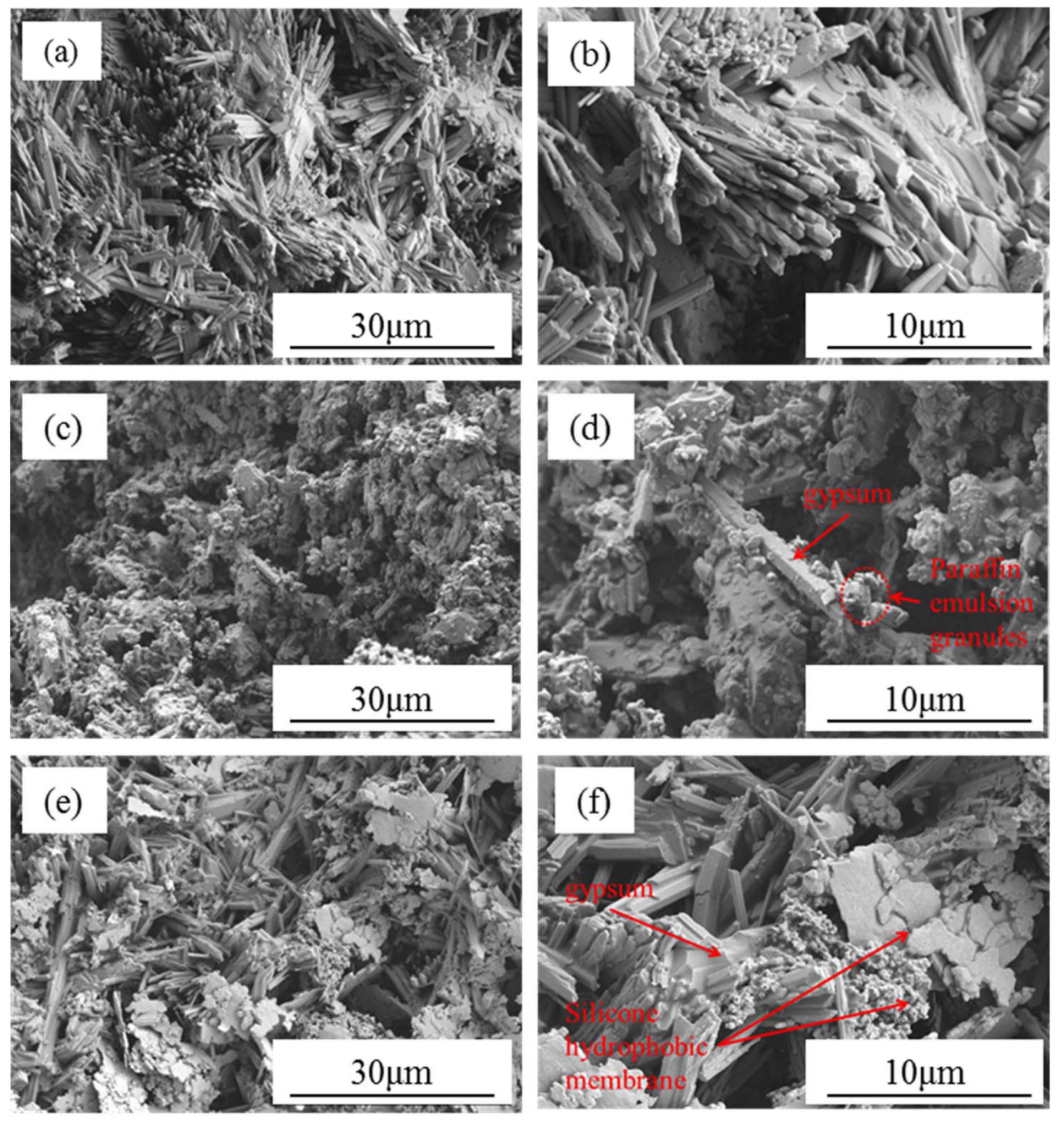

Fig. 11. SEM images of (a, b) a blank gypsum sample, (c, d) a gypsum sample to which $1 \%$ of a paraffin emulsion water repellent is added, and (e, f) a gypsum sample to which a $1 \%$ silicone oil paraffin composite emulsion water repellent is added. 
curing were analyzed by Hitachi Regulus 8230 field emission scanning electron microscope. Fig. 11 shows the SEM photograph of the hydrated products of various gypsum samples in 1800 and 5000 times magnification. Fig. 11(a) and (b) are blank gypsum samples, which predominantly showed that the needle-like crystal structures with large aspect ratios cross each other; the pores between the crystals could be observed from microscopic morphology. Fig. $11(c)$ and (d) were crystal morphologies of $1 \%$ paraffin emulsion gypsum, and the pores between the crystals became smaller than that of the blank gypsum. It can be clearly observed that the paraffin particles were wrapped around the gypsum crystals, thereby preventing the invasion of water. However, the addition of paraffin emulsion caused the rod-like crystal of gypsum needle to change, and the number of needle-like crystals could not be reduced by an orderly crossover; this resulted in a significant decrease in the mechanical strength. Fig. 11(e) and (f) represent a 1\% silicone oil paraffin emulsion gypsum-like blend; it can be observed that the composite emulsion penetrates the gypsum block to form a hydrophobic film with a very low surface tension. Further, the addition of the silicone oil paraffin composite emulsion did not alter the structure of the gypsum crystal, so that the needle-like crystal of the gypsum was overlapped. The pores between the gypsum crystals were reduced, and the compactness of the gypsum test piece was increased; therefore, effective improvement in the waterproofing performance of the gypsum test piece was achieved without adversely affecting its mechanical strength.

\subsection{Waterproof mechanism}

The addition of paraffin emulsion reduced the water absorption of gypsum. As the amount of paraffin emulsion was increased, the water absorption of gypsum was significantly reduced because paraffin was emulsified to form very fine spherical particles, which were suspended in water to form an oil-in-water continuous phase. When the paraffin emulsion was evenly mixed with the gypsum slurry, the hydrophobic material in the emulsion was immediately dispersed in the continuous phase of the gypsum slurry. When the hemihydrate gypsum slurry condensed and hardened, the water in the surrounding hydrophobic material was absorbed. The dehydrated hydrophobic material adsorbed the hydrophobic membrane on the fine network of microporous walls and gypsum hardened structures. The paraffin emulsion encapsulated the gypsum particles in the gypsum slurry. When the gypsum product was exposed to water, it was hindered by the waterproof membrane in the fine network, therefore reducing the water absorption rate. Moreover, the addition of paraffin emulsion has not only reduced the porosity of gypsum but has also increased its compactness; it has also reduced the water absorption of gypsum. ${ }^{20)}$

Although the water absorption rate of the gypsum body can be reduced as the content of the paraffin emulsion increases, the flexural compressive strength, especially the absolute dry strength value was greatly reduced, and the

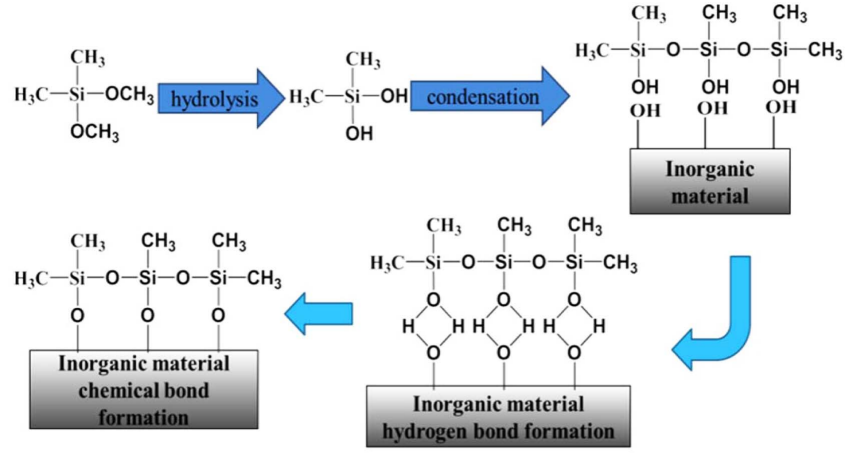

Fig. 12. Waterproof mechanism of dimethicone.

water immersion strength was even lower than that of the blank gypsum. The gypsum particles were encapsulated by the emulsion before coagulation, causing the hydration of the dehydrate gypsum crystals to be blocked, delaying the setting time of the gypsum. This has also resulted in the incomplete formation of gypsum crystals and has therefore reduced the strength of the gypsum body.

This article employs the use of liquid paraffin instead of dimethyl silicone oil to prepare silicone oil paraffin composite emulsion; this is aimed at improving the adverse effect of paraffin emulsion on the dry strength of gypsum block. The water-repellent action mechanism of dimethyl silicone oil (polydimethylsiloxane) is shown in Fig. $12{ }^{21)}$ this action is achieved due to the silicone polymer compound-based water repellent, polydimethylsiloxane intermolecular siloxane group, and a hydroxyl condensation that leads to the formation of a silicone network membrane. This silicone membrane does not block the pores of the material, and so it does not only have the hydrophobicity but also maintains the gas permeability of the material. The silicone oil emulsion can penetrate the gypsum block. Its own -Si-O-chain and -OH is tightly bonded to form a hydrophobic membrane with low surface tension on the pore surface of the block. Water does not penetrate the pores to achieve good water resistance. The silicone oil paraffin composite emulsion-based-waterproofing agent does not only have the advantages of the paraffin emulsion-based waterproofing agent but also effectively reduces the water absorption rate. Moreover, it has a good silicone oil emulsion silicone resin net film, which has an insignificant effect on the strength of the gypsum block and can further improve the softening coefficient of the gypsum. Simultaneously, noteworthy water resistance was exhibited.

\section{Conclusions}

(1) Silicone paraffin composite emulsion-based waterproofing agent was prepared by using liquid paraffin instead of a dimethyl silicone oil. The incorporation of water repellent agents slightly enhances the strength of gypsum test block, and results in the condensation of the siloxane and hydroxyl groups between the dimethyl silicone oil molecules to form 
the silicone film. It does not only have hydrophobicity but also does not adversely affect the strength of gypsum. It is more suitable for the plaster test block than for the traditional liquid paraffin emulsion-based waterproofing agent, and it is composed of FTIR and ${ }^{1} \mathrm{H}-\mathrm{NMR}$. For characterization analysis, the waterproofing agent is obtained by compounding silicone oil with paraffin wax.

(2) The silicone oil paraffin composite emulsion-based waterproofing agent has a significant improvement in the softening coefficient of the gypsum test block compared with the liquid paraffin emulsion-based waterproofing agent. The softening coefficient reaches 0.89 and increases by $60 \%$ when the content was $1 \%$ with the increase in the dosage of waterproofing agent. The water absorption of silicone oil paraffin emulsion composite emulsion is significantly lower than that of the traditional liquid paraffin emulsion-based waterproofing agent. The synthesis of the waterproofing agent has broad application prospects in improving the water-resistance of gypsum.

\section{Acknowledgments}

This work was financially supported by the Anhui Science and Technology Project (1704g07020113).

\section{REFERENCES}

1. P. Mróz and M. Mucha, "Hydroxyethyl Methyl Cellulose as a Modifier of Gypsum Properties," J. Therm. Anal. Calorim., 134 [2] 1083-89 (2018).

2. N. V. Chernysheva, V. S. Lesovik, M. Y. Drebezgova, S. V. Shatalova, and A. H. Alaskhanov, "Composite Gypsum Binders with Silica-Containing Additives," IOP Conf. Ser.: Mater. Sci. Eng., 327032015 (2018).

3. T. L. Li and P. L. Lee, "Structural Evolution of Gypsum under High Pressure: Single-Crystal X-Ray Experiments Revisited," Phys. Chem. Miner., 45 [9] 895-906 (2018).

4. M. Singh and M. Garg, "Retarding Action of Various Chemicals on Setting and Hardening Characteristics of Gypsum Plaster at Different pH,” Cem. Concr. Res., 27 [6] 947-50 (1997)

5. Y. Zhang, F. Pan, and R. Wu, "Study on the Performance of FGD Gypsum-Metakaolin-Cement Composite Cementitious System," Constr. Build. Mater., 128 1-11 (2016).

6. H. Tabatabai, M. Janbaz, and A. Nabizadeh, "Mechanical and Thermo-Gravimetric Properties of Unsaturated Polyester Resin Blended with FGD Gypsum," Constr. Build. Mater., 163 438-45 (2018).

7. M. Wu, X. Hu, Q. Zhang, W. Cheng, and Z. Hu, "Orthogonal Experimental Studies on Preparation of Mine-Filling Materials from Carbide Slag, Granulated Blast-Furnace Slag, Fly Ash, and Flue-Gas Desulphurisation Gypsum," Adv. Mater. Sci. Eng., 20184173520 (2018).
8. F. Q. Zhao, H. J. Liu, L. X. Hao, and Q. Li, "Water Resistant Block from Desulfurization Gypsum," Constr. Build. Mater., 27 [1] 531-33 (2012).

9. A. A. Khalil, A. Tawfik, A. A. Hegazy, and M. F. El-Shahat, "Effect of Some Waste Additives on the Physical and Mechanical Properties of Gypsum Plaster Composites," Constr. Build. Mater., 68 580-86 (2014).

10. C. Zhu, J. Zhang, J. Peng, W. Cao, and J. Liu, "Physical and Mechanical Properties of Gypsum-Based Composites Reinforced with PVA and PP Fibers," Constr. Build. Mater., 163 695-705 (2018).

11. G. N. Pervyshin, G. I. Yakovlev, A. F. Gordina, J. Keriene, I. S. Polyanskikh, H.-B. Fischer, N. R. Rachimova, and A. F. Buryanov, "Water-Resistant Gypsum Compositions with Man-made Modifiers,” Procedia Eng., 172 867-74 (2017).

12. I. Domanskaya, S. Bednyagin, and H. B. Fisher, "WaterResistant Gypsum Binding Agents and Concretes Based Thereof as Promising Materials for Building Green," IOP Conf. Ser.: Earth. Environ. Sci., 177012029 (2018).

13. A. A. Khalil, A. Tawfik, and A. A. Hegazy, "Plaster Composites Modified Morphology with Enhanced Compressive Strength and Water Resistance Characteristics," Constr. Build. Mater., 167 55-64 (2018).

14. Y. Ding and Y. C. Fang. "Comprehensive Utilization of Anhui Industrial By-Product Gypsum (in Chinese)," Mater. Rev., 27, 147-52(2013).

15. Y. Ding, Y. C. Fang, H. Fang, F. J. Zhang, and W. J. Xie, "Research on the New Type of Gypsum Water-Proofing Additive(in Chinese)," Mater. Rev., 29 126-29 (2015).

16. Y. Ding, Y. C. Fang, Q. F. Ren, H. Fang, Q. C. Zhang, and W.-C. Oh, "Study on the Waterproofing Performance of FGD Gypsum Building Products from Inorganic-Organic Composite Additives," Korean J. Mater. Res., 25 590-97 (2015).

17. S. M. Yin and M. C. Li. "Preparation of Composite Emulsion of Dimethyl Silicone Oil-Liquid Paraffin (in Chinese)," Sili. Mater., 27 20-4 (2013).

18. M. Chang, H. L. Yun, Z. Q. Li, R. Zhou, M. J. Zhang, and H. W. Yu. "Infrared Spectroscopy Study of Silicone Oil CSi Stretching Vibration (in Chinese)," Mater. Rev., 30 814 (2016).

19. L. Wang, F. Qiao, Z. W. Hu, Y. Wang, and Y. Zhai, "Paraffin's Dissolution Characteristics and the Infrared Spectroscopy Analysis of it's Dissolution Products (in Chinese)," J. Southwest Pet. Univ., 30 122-25 (2018).

20. Q. G. Zu, Effect of Chemical Additives on Water Resistance of Building Gypsum (in Chinese), in Master's Thesis, Jinan University, Jinan, 2007.

21. K. He, Study on Organic Functional Materials and their Protective Mechanism for Concrete under Harsh Environment (in Chinese), in Ph.D. Thesis, Zhejiang University, HangZhou, 2014. 